\title{
Safety and 6-month effectiveness of minimally invasive sacroiliac joint fusion: a prospective study
}

\author{
This article was published in the following Dove Press journal: \\ Medical Devices: Evidence and Research \\ 12 December 2013 \\ Number of times this article has been viewed
}

\section{Bradley S Duhon' \\ Daniel J Cher ${ }^{2}$ \\ Kathryn D Wine ${ }^{2}$ \\ Harry Lockstadt ${ }^{3}$ \\ Don Kovalsky ${ }^{4}$ \\ Cheng-Lun Soo ${ }^{5}$ \\ On behalf of the SIFI Study Group}

'Neurosurgical and Spine Specialists, Parker, CO, ${ }^{2} \mathrm{SI}-\mathrm{BONE}$, Inc, San Jose, $\mathrm{CA},{ }^{3}$ Bluegrass Orthopaedics and Hand Care, Lexington, KY, ${ }^{4}$ Orthopaedic Center of Southern Illinois, Mount Vernon, IL, ${ }^{5}$ Health Research Institute, Oklahoma City, OK, USA
Correspondence: Daniel J Cher SI-BONE, Inc, 3055 Olin Avenue, Suite 2200, San Jose, CA 95I28, USA $\mathrm{Tel}+\mathrm{I} 6502695763$

Email dcher@si-bone.com
Background: Sacroiliac (SI) joint pain is an often overlooked cause of low back pain. SI joint arthrodesis has been reported to relieve pain and improve quality of life in patients suffering from degeneration or disruption of the SI joint who have failed non-surgical care. We report herein early results of a multicenter prospective single-arm cohort of patients with SI joint degeneration or disruption who underwent minimally invasive fusion using the iFuse Implant System ${ }^{\circledR}$.

Methods: The safety cohort includes 94 subjects at 23 sites with chronic SI joint pain who met study eligibility criteria and underwent minimally invasive SI joint fusion with the iFuse Implant System $^{\circledR}$ between August 2012 and September 2013. Subjects underwent structured assessments preoperatively, immediately postoperatively, and at 1, 3, and 6 months postoperatively, including SI joint and back pain visual analog scale (VAS), Oswestry Disability Index (ODI), Short Form-36 (SF-36), and EuroQoL-5D (EQ-5D). Patient satisfaction with surgery was assessed at 6 months. The effectiveness cohort includes the 32 subjects who have had 6-month follow-up to date.

Results: Mean subject age was 51 years ( $n=94$, safety cohort) and $66 \%$ of patients were women. Subjects were highly debilitated at baseline (mean VAS pain score 78, mean ODI score 54). Three implants were used in $80 \%$ of patients; two patients underwent staged bilateral implants. Twenty-three adverse events occurred within 1 month of surgery and 29 additional events occurred between 30 days and latest follow-up. Six adverse events were severe but none were device-related. Complete 6-month postoperative follow-up was available in 26 subjects. In the effectiveness cohort, mean ( \pm standard deviation) SI joint pain improved from a baseline score of $76( \pm 16.2)$ to a 6-month score of $29.3( \pm 23.3$, an improvement of 49 points, $P<0.0001)$, mean ODI improved from $55.3( \pm 10.7)$ to $38.9( \pm 18.5$, an improvement of 15.8 points, $P<0.0001)$ and SF-36 PCS improved from $30.7( \pm 4.3)$ to $37.0( \pm 10.7$, an improvement of 6.7 points, $P=0.003$ ). Ninety percent of subjects who were ambulatory at baseline regained full ambulation by month 6 ; median time to full ambulation was 30 days. Satisfaction with the procedure was high at $85 \%$.

Conclusion: Minimally invasive SI joint fusion using the iFuse Implant System ${ }^{\circledR}$ is safe. Mid-term follow-up indicates a high rate of improvement in pain and function with high rates of patient satisfaction.

Keywords: minimally invasive surgery, sacroiliac joint, sacroiliac joint arthrodesis, spine surgery, prospective clinical trial

\section{Background}

Pain caused by disorders of the sacroiliac (SI) joint can be difficult to distinguish from that of the hip or lumbar spine, leaving it as an overlooked source of pain. While provocative physical examination findings can suggest the SI joint as a pain generator, no particular set of signs or symptoms accurately diagnoses SI joint problems. 
Radiographic abnormalities are typically subtle and have not been found to correlate with pain generation. ${ }^{1,2}$ The current reference standard for confirming that the SI joint is a pain generator is a marked decrease in pain following an imageguided intra-articular SI joint block.

In the early 1900s, the SI joint was often suspected as a cause of chronic lower back pain (LBP). ${ }^{3}$ However, as increasingly sophisticated methods of diagnosing spinal pathologies (eg, facet arthropathy, lumbar spondylosis, and disc herniation) became available, less focus was placed on the SI joint. Nonetheless, SI joint pain is exceedingly common. In two large retrospective reviews of patients referred for outpatient evaluation of chronic lower back pain, SI joint pain was a common diagnosis, occurring in $14 \%$ and $22 \%$ of cases, respectively. ${ }^{4,5}$ Amongst patients evaluated for residual offcenter LBP after lumbar fusion, a diagnosis of SI joint pain can be made in approximately $40 \%$ of patients. ${ }^{6,7}$

Open arthrodesis of the SI joint was first reported in the 1920s. A small number of retrospective cohorts ${ }^{8,9}$ suggest that SI joint arthrodesis can be effective for relieving chronic LBP. However, open SI joint fusion has waned in popularity as it requires relatively large incisions, lengthy hospital stays, lengthy recovery periods (often lasting months) and has a relatively high complication rate (13.7\% in one systematic review) ${ }^{10}$ and a high rate of reported non-union $(9 \%-41 \%){ }^{8,11,12}$ Patient satisfaction with open SI joint fusion surgery has also been highly variable $(18 \%-80 \%)$ in reported series. ${ }^{10}$

Minimally invasive SI joint fusion has become available with various devices. ${ }^{9,13-15}$ Several recent retrospective reports show promising outcomes with the placement of a series of triangular titanium porous plasma spray (TPS) coated implants (iFuse Implant System ${ }^{\circledR}$, SI-BONE Inc, San Jose, CA, USA) across the SI joint. ${ }^{15-20}$ Herein we report safety and midterm (6-month) effectiveness results of an ongoing multicenter, prospective clinical trial of minimally invasive SI joint fusion using the iFuse Implant System ${ }^{\circledR}$.

\section{Methods}

Sacroiliac Joint Fusion with iFuse Implant System ${ }^{\circledR}$ (SIFI) is an ongoing prospective, multicenter single-arm clinical trial. Clinical trial enrollment began in August 2012. As of September 2013, 23 centers are participating. The study protocol (registered on clinicaltrials.gov [NCT01640353] ${ }^{21}$ ) was institutional review board (IRB) approved at each participating clinical site prior to patient enrollment. The study was sponsored by the device's manufacturer (SI-BONE, Inc., San Jose, CA, USA).

Patients were invited to participate if they were between the ages of 21 and 70 and had a diagnosis of degenerative sacroiliitis (based on a history of prior lumbar fusion or radiographic findings of degeneration) and/or SI joint disruption (based on leakage of contrast during diagnostic SI joint block or joint asymmetry on radiographic imaging). To confirm the diagnosis, patients must have: a history of SI joint pain, positive provocative testing suggesting the SI joint as the pain generator, and at least a $50 \%$ decrease of pain after image-guided injection into the SI joint with local anesthetic within 3 months prior to screening. Inclusion also required a baseline score of at least $30 \%$ on the Oswestry Disability Index (ODI) and an SI joint pain score of at least 50 on a $0-100 \mathrm{~mm}$ visual analog scale (VAS).

Patients were excluded if they met any of the following conditions: severe back pain due to other causes (eg, lumbar disc degeneration, spinal stenosis, etc), history of recent $(<1$ year ago) major trauma to the pelvis, metabolic bone disease (either induced or idiopathic), or any condition that made treatment with the study devices infeasible or interfered with ability to participate in physical therapy. Patients involved in litigation, on disability, or receiving worker's compensation related to their back or SI joint pain were also excluded. Patients who agreed to enroll signed a study-specific consent form.

Baseline assessments included a detailed medical history, physical examination, and quality of life questionnaires including VAS pain measurement, ODI, ${ }^{22}$ EuroQoL-5D (EQ-5D), ${ }^{23}$ and Short Form-36 (SF-36). ${ }^{24}$ VAS is a $0-100 \mathrm{~mm}$ line upon which the patient places a mark to denote current level of SI joint pain, where $0=$ no pain and 100 represents worst imaginable pain. ODI is a validated ten-question survey that measures the degree of disability due to back pain. EQ-5D is a generic, five-question broad quality of life measure that can be combined into a single index that represents the time trade-off (TTO) utility of current health. EQ-5D also includes a $0-100 \mathrm{~mm}$ health thermometer, where 0 means death and 100 means perfect health. SF-36 is a 36-question 8-subscaled generic quality of life measure. SF-36 physical component summary (PCS) summarizes overall physical health, with population norms with mean 50 and standard deviation of 10.0. Similarly SF-36 mental component summary (MCS) summarizes overall mental health, with similar population norms.

Subjects underwent minimally invasive SI joint fusion (as described by Rudolf ${ }^{15}$ and Sachs ${ }^{17}$ ) within 30 days of their baseline assessment. Briefly, the patient is placed in the prone position on a radiolucent table to facilitate the use of intraoperative fluoroscopy. After general endotracheal anesthesia is administered, the patient is prepped in the normal sterile fashion. A $3 \mathrm{~cm}$ lateral incision is made into the buttock region and the gluteal fascia is bluntly dissected 
to reach the outer table of the ilium. A Steinmann pin is passed through the ilium across the SI joint to the center of the sacrum lateral to the neural foramen. After a soft tissue protector is passed over the pin, a drill is used to create a pathway and decorticate the bone. A triangular broach is then used to further decorticate the bone and prepare the pathway to receive the first implant. Using a pin guidance system, two to four implants are placed. The most cephalad implant is seated within the sacral ala. The second implant is generally located above or adjacent to the $\mathrm{S} 1$ foramen and the third between the S1 and S2 foramen (Figure 1). The incision is then irrigated and the tissue layers are sequentially closed. Subjects requiring treatment of both SI joints could undergo either bilateral same-day surgery or staged surgery, with the second procedure occurring within 60 days of the initial procedure. Perioperative measures, including estimated blood loss, fluoroscopy time, operating time, devices used, and complications, were collected. Subjects were discharged home at the surgeon's discretion. Prior to discharge, subjects were re-evaluated for the occurrence of adverse events.

Postoperatively, subjects were asked to remain at heel-toe touch-down weight-bearing using a front-wheeled walker or crutches for 3 weeks followed by progressive ambulation with crutches until fully ambulatory. Beginning 1 to 3 weeks postoperatively, subjects were asked to undergo individualized physical therapy twice a week for 6 weeks. Physical therapy involved activity modification to minimize pain recurrence, mobility and stability exercises, as well as adjacent segment joint mobilization for stiffness and pain control. Manipulation of the treated SI joint was discouraged.

Subjects underwent in-clinic follow-up visits at 1, 3 and 6 months consisting of review of adverse changes in health, ambulatory and work status, medication use for pain, physical examination, and quality of life questionnaires. Additional study visits will occur at 12, 18, and 24 months including a high-resolution pelvic CT scan at 12 months. Pelvic X-rays were taken at 3 and 6 months and will be repeated at 24 months. Radiographic study outcomes will be reported elsewhere.

\section{Device description}

The iFuse Implant System ${ }^{\circledR}$ is an FDA cleared (K080398) titanium implant that is triangular in shape on cross section and coated with a porous TPS (Figure 2). The triangular shape combined with an interference fit is designed to minimize micromotion and rotation. Porous plasma spray coating allows biological fixation of bone and has been used in several orthopedic devices, such as hip, knee, and shoulder implants, and artificial discs, for many years with favorable results. iFuse devices are available in multiple configurations ranging from $30-70 \mathrm{~mm}$ in length and 4 and $7 \mathrm{~mm}$ in inscribed diameter. Typically, three implants are placed across the SI joint; the manufacturer's instructions require the placement of at least 2 implants per side.

\section{Cohorts, study endpoints, and statistical analysis}

Herein we report on two cohorts: 1) the safety cohort is all study subjects who underwent the study surgical procedure from August 2012 through early September 2013; 2) the effectiveness cohort is all consecutive study subjects who underwent the study procedure prior to April 2013, who now have least 6 months of follow-up. Baseline characteristics of subjects in the safety cohort and effectiveness cohorts were compared using $t$-tests or chi-squared tests.

The primary study endpoint, evaluated at 6 months after the most recent SI joint fusion (to accommodate patients with staged bilateral surgery), is a binary success/failure composite endpoint. A subject is considered a success if all of the following are met: reduction from baseline VAS SI joint pain

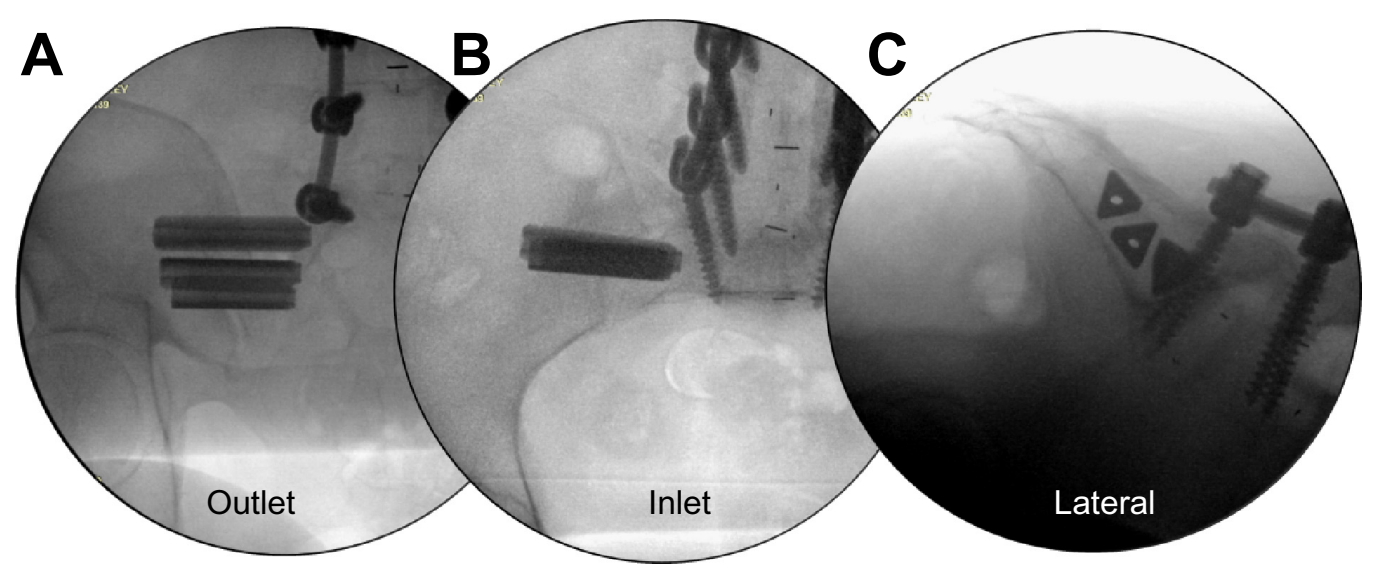

Figure I Intraoperative fluoroscopic images showing post-placement outlet (A), inlet (B), and lateral (C) views. 


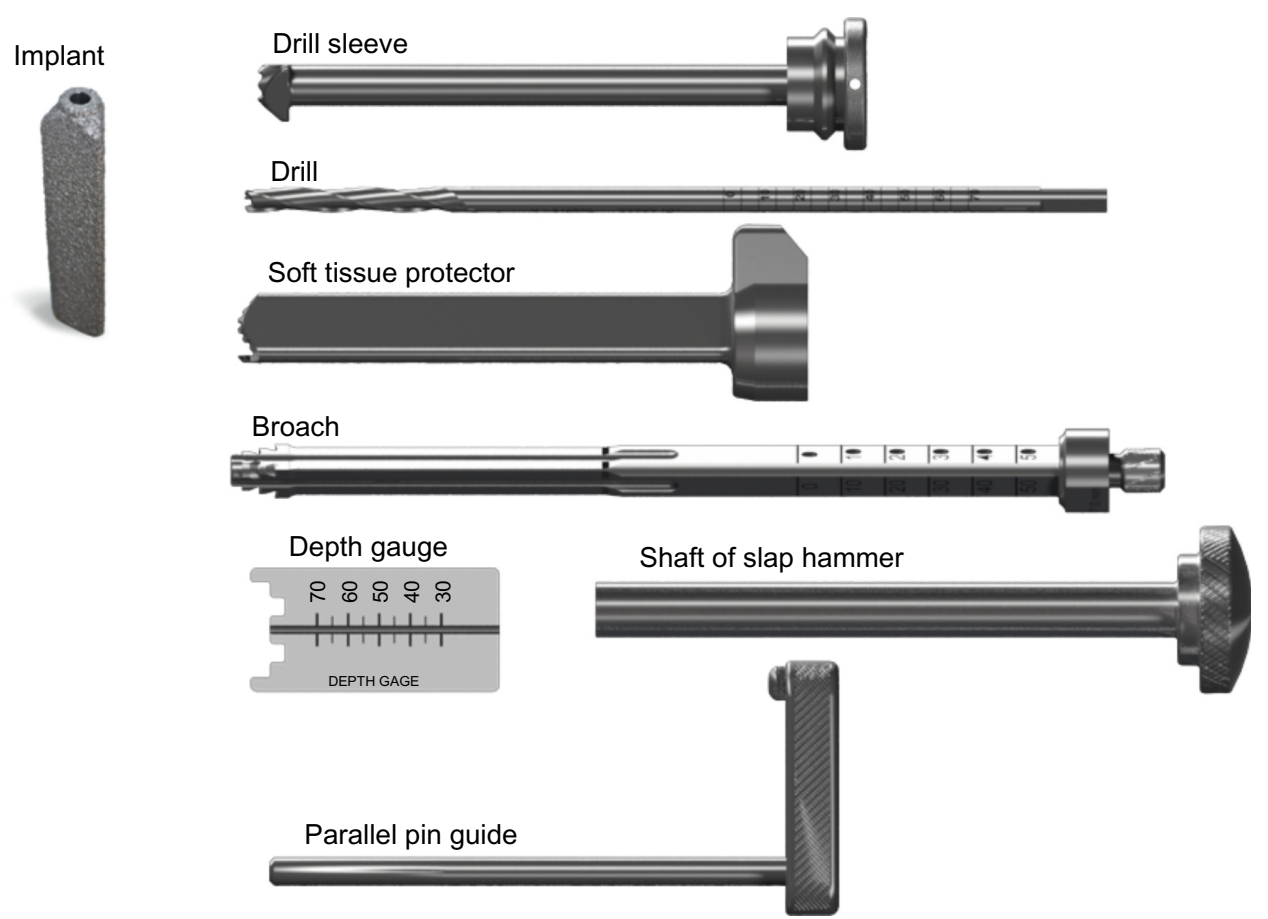

Figure 2 iFuse implant (SI-BONE Inc, San Jose, CA, USA ) (left) and delivery system components (right).

by at least $20 \mathrm{~mm} /$ points, absence of device-related serious adverse event, absence of neurological worsening related to the sacral spine, and absence of surgical re-intervention (removal, revision, reoperation, or supplemental fixation) for SI joint pain. The $20 \mathrm{~mm}$ threshold was selected as the minimally clinically important difference in chronic lower back pain. ${ }^{25}$ The proportion of subjects meeting the success criteria was calculated using a modified intent-to-treat approach.

The study's secondary endpoints include an analysis of patient success rates at other time points, and improvement from baseline in VAS, ODI, SF-36 PCS, and EQ-5D scores. For continuous variables, changes from baseline were compared using repeated measure analysis of variance. All statistical analyses were performed using SAS 9.0 (SAS Institute Inc, Cary, NC, USA).

\section{Results}

We report baseline and procedure characteristics on the first 94 subjects at 23 sites who underwent the study procedure (ie, the safety cohort) and mid-term effectiveness results in the first 32 subjects who have reached 6 months of follow up (ie, the effectiveness cohort). All subjects met eligibility criteria except for the following: five subjects did not meet all inclusion criteria (two subjects were $>70$ year of age, one subject had SI joint pain for slightly less than 6 months, one subject was not diagnosed with SI joint pain per all protocol requirements, and in one subject, the screening SI joint pain was slightly below the $50 \mathrm{~mm}$ threshold for inclusion) and
12 met one of the exclusion criteria (one had severe residual non-SI-joint back pain, one had osteoporosis, one had rheumatoid arthritis and nine subjects were involved in workers compensation or injury litigation related to chronic LBP).

\section{Baseline characteristics}

Patient characteristics are listed in Table 1. There were no meaningful differences in characteristics between the subjects in the effectiveness cohort and subjects in the safety cohort. Subjects averaged 51 years old, were mostly Caucasian (91\%) and approximately two-thirds were female. Subjects were highly debilitated by SI joint pain, as determined by high baseline pain (mean 78 on the $0-100$ scale) and ODI scores (mean 54). Quality of life was substantially diminished, as indicated by low EQ-5D scores (mean of 45 on TTO and 56 on health thermometer) and low SF-36 scores (mean PCS of 30.7 and MCS of 41.0). Three-quarters of patients were taking narcotics, and all reported multiple activities that worsened SI joint pain. Many (62\%) had a history of prior lumbar fusion, and concomitant spine disease was common. Pain associated with the SI joint was most common in the posterior superior iliac spine, but distant and/or radiating pain was common anteriorly and posteriorly (Figure 3 ).

\section{Procedure characteristics}

Ninety-four subjects in the safety cohort underwent the study procedure. All study procedures were performed according to the manufacturer's instructions for use. Mean (standard deviation $[\mathrm{SD}])$ procedure time was $48( \pm 16)$ minutes, with 
Table I Characteristics of effectiveness and safety cohorts

\begin{tabular}{|c|c|c|c|c|c|c|}
\hline & \multicolumn{2}{|c|}{$\begin{array}{l}\text { Effectiveness cohort } \\
(\mathrm{n}=32)\end{array}$} & \multicolumn{2}{|c|}{$\begin{array}{l}\text { Safety cohort } \\
(n=94)\end{array}$} & \multicolumn{2}{|l|}{$P$-value* } \\
\hline Age, mean $( \pm S D)$ & \multicolumn{2}{|l|}{$50.2(12.6)$} & \multicolumn{2}{|l|}{$51.2(10.8)$} & \multicolumn{2}{|l|}{0.5128} \\
\hline Sex (n, \% female) & \multicolumn{2}{|l|}{$21(66 \%)$} & \multicolumn{2}{|l|}{62 (66\%) } & \multicolumn{2}{|l|}{0.9610} \\
\hline White race $(\mathrm{n}, \%)$ & \multicolumn{2}{|l|}{$32(100 \%)$} & \multicolumn{2}{|l|}{$89(95 \%)$} & \multicolumn{2}{|l|}{0.4359} \\
\hline Hispanic or Latino (n, \%) & \multicolumn{2}{|l|}{$0(0 \%)$} & \multicolumn{2}{|l|}{$3(3.2 \%)$} & \multicolumn{2}{|l|}{0.2060} \\
\hline Body mass index, mean $( \pm S D)$ & \multicolumn{2}{|l|}{$31.4(7.3)$} & \multicolumn{2}{|l|}{$29.8(7.2)$} & \multicolumn{2}{|l|}{0.1026} \\
\hline Current smoker (n, \%) & \multicolumn{2}{|l|}{ II (34\%) } & \multicolumn{2}{|l|}{$30(32 \%)$} & \multicolumn{2}{|l|}{0.6847} \\
\hline Ambulatory without assistance (n, \%) & \multicolumn{2}{|l|}{$29(91 \%)$} & \multicolumn{2}{|l|}{87 (93\%) } & \multicolumn{2}{|l|}{0.6089} \\
\hline Work status (n, \%) & & & & & & \\
\hline Working full time & $10(31 \%)$ & & $32(34 \%)$ & & 0.6097 & \\
\hline Not working due to SI joint pain & 14 (44\%) & & $36(38 \%)$ & & & \\
\hline Prior lumbar fusion (n, \%) & $22(69 \%)$ & & $58(62 \%)$ & & 0.5435 & \\
\hline Months of pain, mean $( \pm S D)$ & $53.6(94.3)$ & & $60.8(84.2)$ & & 0.5547 & \\
\hline Pain syndrome & & & & & & \\
\hline Pain began peripartum & $6(19 \%)$ & & 12 (13\%) & & 0.2928 & \\
\hline Pain radiates down leg & $31(97 \%)$ & & 79 (84\%) & & 0.0198 & \\
\hline Groin pain & $20(63 \%)$ & & $55(59 \%)$ & & 0.6330 & \\
\hline Pain worse with sitting & $28(88 \%)$ & & $83(88 \%)$ & & 0.6936 & \\
\hline Pain worse with rising & $25(78 \%)$ & & $72(77 \%)$ & & 0.9062 & \\
\hline Pain worse with walking & $28(88 \%)$ & & $80(85 \%)$ & & 0.7658 & \\
\hline Pain worse with climbing stairs & $28(88 \%)$ & & $82(87 \%)$ & & 0.8844 & \\
\hline Pain worse descending stairs & $19(59 \%)$ & & $65(69 \%)$ & & 0.1093 & \\
\hline Prior treatments & & & & & & \\
\hline Physical therapy & $23(72 \%)$ & & $60(64 \%)$ & & 0.2827 & \\
\hline Steroid SI joint injection & $32(100 \%)$ & & $89(95 \%)$ & & 0.1387 & \\
\hline RF ablation & $3(9 \%)$ & & $10(11 \%)$ & & $0.756 \mathrm{I}$ & \\
\hline Taking narcotics $(\mathrm{n}, \%)$ & $24(75 \%)$ & & 74 (79\%) & & 0.5263 & \\
\hline Proportion with lumbar stenosis (n, \%) & $10(31 \%)$ & & $23(25 \%)$ & & 0.4896 & \\
\hline Proportion with hip diagnosis (n, \%) & $3(9 \%)$ & & $11(12 \%)$ & & $0.6|4|$ & \\
\hline & Left & Right & Left & Right & Left & Right \\
\hline Physical exam findings & & & & & & \\
\hline FABER/Patrick's & 17 (94\%) & $13(93 \%)$ & $38(90 \%)$ & $45(88 \%)$ & 0.2401 & 0.8457 \\
\hline Compression & 16 (89\%) & II (79\%) & $34(81 \%)$ & $40(78 \%)$ & 0.6525 & 0.9329 \\
\hline Thigh thrust & 14 (78\%) & $14(100 \%)$ & 31 (74\%) & $44(86 \%)$ & 0.6691 & 0.3810 \\
\hline Distraction & II (6I\%) & $8(57 \%)$ & $27(64 \%)$ & $28(55 \%)$ & 0.7368 & 0.9265 \\
\hline Gaenslen & $9(50 \%)$ & $7(50 \%)$ & $22(52 \%)$ & $31(61 \%)$ & 0.5066 & 0.5787 \\
\hline VAS pain score, mean $( \pm S D)$ & $76.2(16.2)$ & & $77.8(13.9)$ & & 0.4008 & \\
\hline ODI score, mean $( \pm S D)$ & $55.3(10.7)$ & & $54.0(11.0)$ & & 0.7219 & \\
\hline SF-36, mean $( \pm S D)$ & & & & & & \\
\hline PCS & $30.7(5.3)$ & & $31.8(5.8)$ & & 0.1854 & \\
\hline MCS & $41.0(9.6)$ & & $40.0(11.1)$ & & 0.5318 & \\
\hline EQ-5D & & & & & & \\
\hline TTO index & $43.0(16.7)$ & & $45.2(17.9)$ & & 0.3956 & \\
\hline Health thermometer & $53.8(21.3)$ & & $55.7(22.8)$ & & 0.5697 & \\
\hline
\end{tabular}

Note: *P-values compare effectiveness cohort versus those enrolled but not in the effectiveness cohort.

Abbreviations: EQ-5D, EuroQoL-5D; FABER, Flexion, ABduction, External Rotation, and Extension; MCS, mental component summary; ODI, Oswestry Disability Index; PCS, physical component summary; RF, radiofrequency; SD, standard deviation; SI, sacroiliac; SF-36, Short Form-36; SI, sacroiliac; TTO, time trade-off; VAS, visual analog scale.

a range of 20-111 minutes (Table 2). Seventy-seven percent of procedures lasted less than 1 hour. Mean (SD) fluoroscopy time was minimal at $3( \pm 2)$ minutes (range 0.3-11.5). Mean (SD) estimated blood loss was $59 \mathrm{cc}( \pm 96$; range 5-800 cc). One subject had $800 \mathrm{cc}$ estimated blood loss due to injury to the superior gluteal artery. In most cases (75 patients, 80\%) three implants were used; two and four implants were used in five $(5 \%)$ and $14(15 \%)$ cases, respectively. Most implants were $7 \mathrm{~mm}$ in diameter. Three device-related complications occurred (all three were cases of excessive pin advancement, all at one study site), without consequence. Mean hospital length of stay was 0.79 days; 35 (37\%) subjects were discharged on the same hospital day, 54 subjects (57\%) stayed overnight, and five subjects had a length of stay $>1$ day $(2,3$, 3,5 , and 7 days each). Prolonged hospital stays were related to patient comorbidities not procedure-related adverse events. 

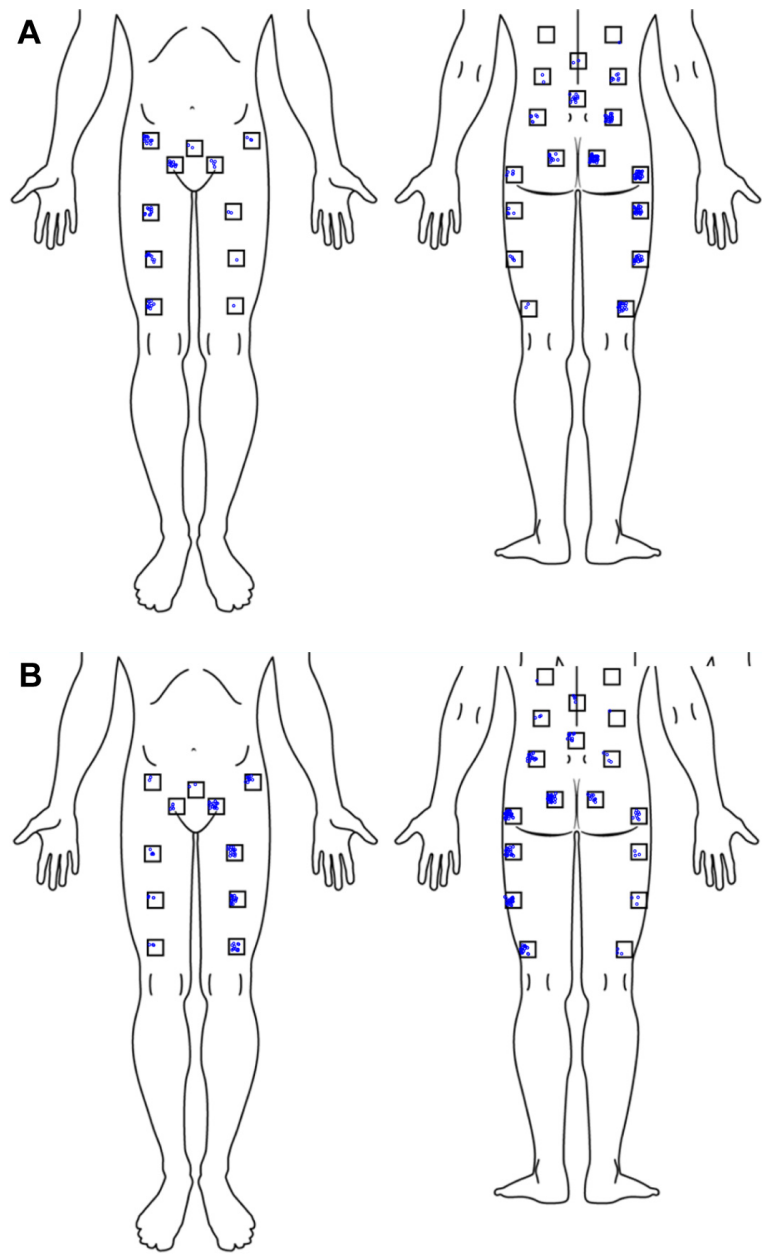

Figure 3 Pain location by target sacroiliac joint side (A) right-sided pain, (B) leftsided pain. Each jittered dot represents a subject self-report of pain.

\section{Subject trial flow}

To date, two effectiveness cohort subjects voluntarily withdrew at days 227 and 240 after surgery for reasons unrelated to outcomes or adverse events. One of these subjects completed the 6-month visit. One additional effectiveness cohort patient refused to attend the 6-month visit, one underwent staged bilateral SI joint fusion (and the 6-month visit is not yet due), and three 6-month visits are delayed, leaving 26 subjects in the effectiveness cohort with reportable 6-month outcomes.

\section{Pain and quality of life outcomes}

During follow-up, mean (SD) SI joint pain in the effectiveness cohort improved from a baseline of 76 to 42 at 1 month, 26 at 3 months and 26 at 6 months; improvements from baseline at 1,3 , and 6 months $(-37,-49$, and -49 points, respectively) were statistically significant (Table 3 ). Sixty-six percent, $90 \%$, and $89 \%$ of subjects had SI joint pain VAS decreases of 20 or more mm at 1,3, and 6 months, respectively. Twenty-three of $26(88.5 \%)$ subjects met the study's success criterion at 6 months. Of the three subjects
Table 2 Index procedure characteristics ( $\mathrm{n}=94$ ); five subjects had contralateral implants placed during a second procedure

\begin{tabular}{|c|c|}
\hline Characteristic & $\mathbf{N}(\%)$ or mean \pm SD (range) \\
\hline \multicolumn{2}{|l|}{ Target joint, n (\%) } \\
\hline Right & $47(50 \%)$ \\
\hline Left & $47(50 \%)$ \\
\hline \multicolumn{2}{|l|}{ Procedure time } \\
\hline Mean (SD, range) & $48.2 \pm I 6.1(20-11 I)$ \\
\hline$<60$ minutes, $\mathrm{n}(\%)$ & $72(77 \%)$ \\
\hline 60-120 minutes, $\mathrm{n}(\%)$ & $21(23 \%)$ \\
\hline \multicolumn{2}{|l|}{ Fluoroscopy time } \\
\hline Mean (SD, range) & $2.7 \pm I .7(0.3-I I .5)$ \\
\hline$<3$ minutes, $\mathrm{n}(\%)$ & $54(58 \%)$ \\
\hline$>3$ minutes, $\mathrm{n}(\%)$ & $39(42 \%)$ \\
\hline \multicolumn{2}{|l|}{ Estimated blood loss } \\
\hline Mean (SD, range) & $59 \pm 96(5-800)$ \\
\hline$<50 \mathrm{cc}$ & $70(75 \%)$ \\
\hline $50-100 \mathrm{cc}$ & $13(14 \%)$ \\
\hline$>100 \mathrm{cc}$ & $10(11 \%)$ \\
\hline \multicolumn{2}{|l|}{ iFuse devices used, n (\%) } \\
\hline 2 & $5(5 \%)$ \\
\hline 3 & $75(80 \%)$ \\
\hline 4 & 14 (15\%) \\
\hline \multicolumn{2}{|l|}{ Implant length, n (\%) } \\
\hline $30 \mathrm{~mm}$ & $9(3 \%)$ \\
\hline $35 \mathrm{~mm}$ & $44(15 \%)$ \\
\hline $40 \mathrm{~mm}$ & $78(27 \%)$ \\
\hline $45 \mathrm{~mm}$ & $72(25 \%)$ \\
\hline $50 \mathrm{~mm}$ & $53(18 \%)$ \\
\hline $55 \mathrm{~mm}$ & $24(8 \%)$ \\
\hline $60 \mathrm{~mm}$ & $5(2 \%)$ \\
\hline $65 \mathrm{~mm}$ & $4(1 \%)$ \\
\hline $70 \mathrm{~mm}$ & $2(0.7 \%)$ \\
\hline Total & 291 (100\%) \\
\hline \multicolumn{2}{|l|}{ Implant diameter, n (\%) } \\
\hline $4 \mathrm{~mm}$ & II (4\%) \\
\hline $7 \mathrm{~mm}$ & $280(96 \%)$ \\
\hline Total & $291(100 \%)$ \\
\hline
\end{tabular}

Abbreviation: SD, standard deviation.

who had $<20$-point improvement in SI joint VAS, one had fallen in the bathtub 2 days prior to the study visit and one had failed to disclose pending litigation regarding a back injury.

ODI score in the effectiveness cohort improved from a mean baseline score of 55.3 to 47.8 at 1 month, 40.4 at 3 months, and 38.9 at 6 months; the improvements from baseline in ODI at 1 , 3 , and 6 months $(-7.5,-14.3$, and -15.8 points, respectively) were statistically significant. At 6 months, 14 (54\%) subjects had an ODI improvement of ten or more points.

Quality of life was measured using two surveys: EQ-5D and SF-36. EQ-5D time trade-off index improved from 43 at baseline to 65 at follow-up, a 23-point improvement $(P=0.0002)$. The EQ-5D global health thermometer rating improved from 54 to 65 (an increase of ten points, $P=0.1111)$. SF-36 PCS and MCS were depressed at baseline (mean 30.7 and 41.0, respectively); by 6 months after SI joint 
Table 3 Change in pain, Oswestry Disability Index, SF-36, and EQ-5D (effectiveness cohort)

\begin{tabular}{|c|c|c|c|c|c|}
\hline Measure & Baseline $(n=32)$ & Month I $(n=32)$ & Month $3(n=30)$ & Month $6(n=26)$ & $P$-value* \\
\hline \multirow[t]{2}{*}{ VAS SI joint pain } & $76.2(16.2)$ & $41.6(28.9)$ & $26.1(22.7)$ & $29.3(23.3)$ & $<0.0001$ \\
\hline & & $-34.6(31.8)$ & $-49.3(23.5)$ & $-48.6(25.3)$ & \\
\hline \multirow[t]{2}{*}{ ODI } & $55.3(10.7)$ & $47.8(14.7)$ & $40.4(15.6)$ & $38.9(18.5)$ & $<0.0001$ \\
\hline & & $-7.5(14.3)$ & $-14.3(16.4)$ & $-15.8(19.9)$ & \\
\hline \multicolumn{6}{|l|}{ EQ-5D } \\
\hline \multirow[t]{2}{*}{ TTO index } & $43.0(16.7)$ & - & - & $65.3(19.5)$ & 0.0006 \\
\hline & & & & $+21.4(26.2)$ & \\
\hline \multirow[t]{2}{*}{ Health thermometer } & $53.8(21.3)$ & - & - & $64.8(21.9)$ & 0.11111 \\
\hline & & & & $+10.4(30.7)$ & \\
\hline \multicolumn{6}{|l|}{ SF-36 } \\
\hline \multirow[t]{2}{*}{ PCS } & $30.7(4.3)$ & - & - & $37.0(10.7)$ & 0.003 \\
\hline & & & & $+6.7(10.3)$ & \\
\hline \multirow[t]{2}{*}{ MCS } & $41.0(9.6)$ & - & - & $47.1(12.2)$ & 0.008 \\
\hline & & & & $+5.8(10.2)$ & \\
\hline \multicolumn{6}{|l|}{ Satisfaction } \\
\hline$\%$ somewhat or very satisfied & - & - & - & $22(85 \%)$ & - \\
\hline$\%$ might or definitely have & - & - & - & $22(85 \%)$ & - \\
\hline implant again & & & & & \\
\hline
\end{tabular}

Notes: Each row shows group mean and SD (upper) and mean and SD change from baseline (lower). *Repeated measures analysis of variance (VAS, ODI, SF-36) or $t$-test (EQ-5D). A dash indicates not required in protocol.

Abbreviations: EQ-5D, EuroQoL-5D; MCS, mental component summary; ODI, Oswestry Disability Index; PCS, physical component summary; SD, standard deviation; SF-36, Short Form-36; SI, sacroiliac; TTO, time trade-off; VAS, visual analog scale.

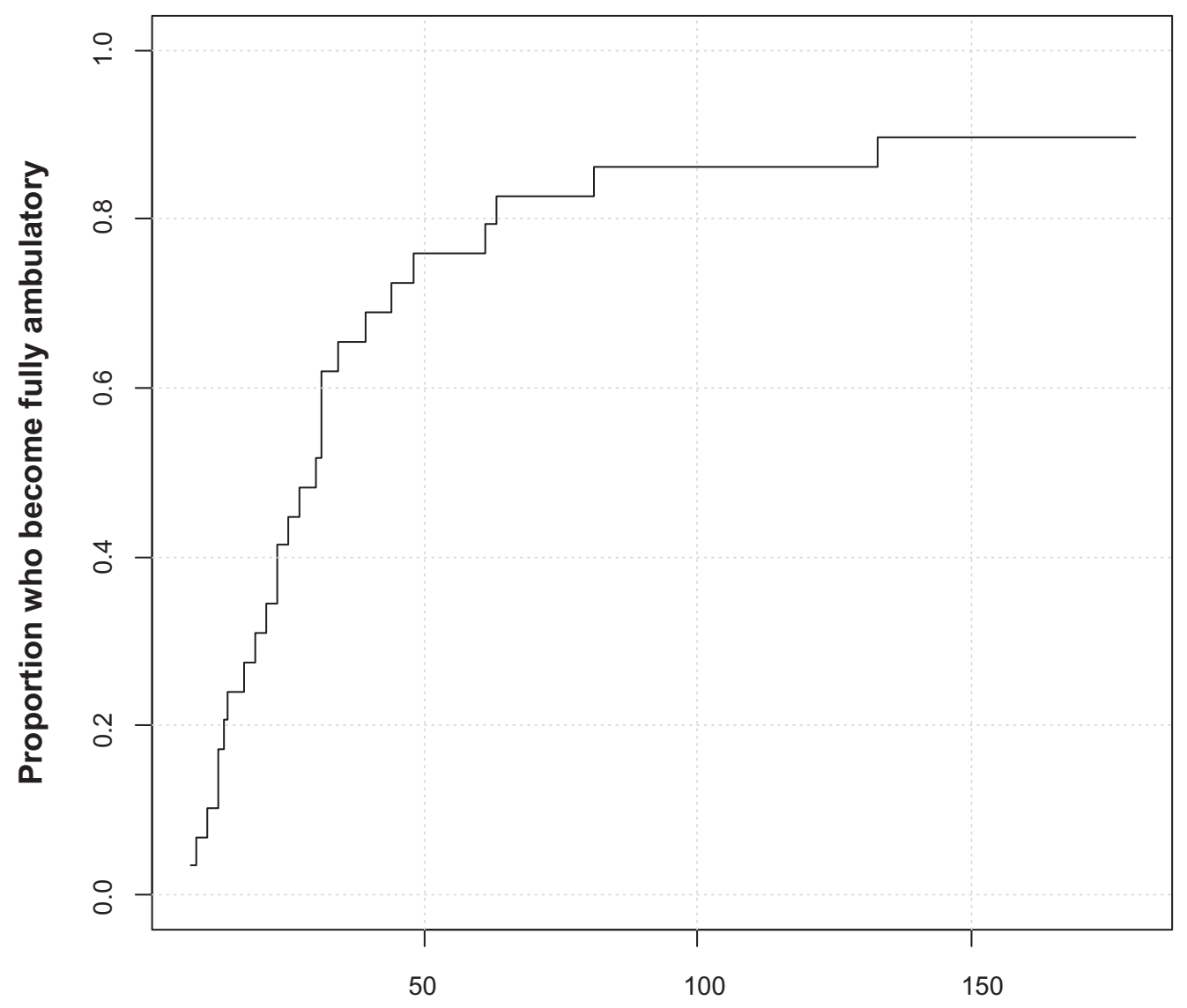

Days since surgery

Figure 4 Time to full ambulation amongst patients who were fully ambulatory at baseline. 
fusion, these values improved by 6.7 and 5.8 points, respectively ( $P=0.003$ and $P=0.008)$. The majority of subjects $(22 / 26,85 \%)$ noted that they were somewhat or very satisfied; $22 / 26(85 \%)$ noted that they would have the procedure again.

Among the 29 subjects who were walking prior to surgery, median time to full ambulation postoperatively was 30 days (Figure 4) and 26 of 29 subjects (90\%) were fully ambulatory by 6 months. Of the three patients who did not regain full ambulation, one had cervical myelopathy, one had back pain from another source and was involved in litigation, and one had episodes of cholecystitis and choledocholithiasis that delayed full ambulation.

\section{Adverse events}

Of the 94 subjects in the safety cohort, 53 adverse events occurred in 34 subjects (Table 4). Twenty-three events occurred in the first 30 days, 29 occurred after postoperative day 30, and date of onset was not known in one. No subject had postoperative neuropathy or underwent implant revision or removal.

Six adverse events were severe, including one case each of: bowel obstruction 6 days after SI joint surgery, deep venous thrombosis at day 4 , pneumonia at day 31 requiring hospitalization, immediate postoperative nausea and vomiting prolonging hospitalization, wound infection at day 74 , and acute cholecystitis at day 145 . Of these, none were rated as related to the study device and only two were probably or definitely procedure-related.

Two subjects had postoperative buttocks pain rated as possibly related to iFuse; in both cases, the subjects had bent over acutely following their surgery, exacerbating pain.

Six adverse events were rated as probably or definitely related to the study procedure, including two cases of postoperative nausea (one severe), two wound infections, one cellulitis, and one exacerbation of buttock pain with initiation of postoperative physical therapy. None of these were reported by the investigator to be related to the implant itself.

\section{Discussion}

The SI joint has been recognized as a pain generator since the early 1900s. ${ }^{3}$ With the 1934 publication by Mixter and Barr ${ }^{26}$ identifying the intervertebral disc as a source of low back and radicular pain, the SI joint seemed to have fallen from the collective conscience in the spine community. Recent publications, however, have reaffirmed the SI joint as a significant contributor to LBP. ${ }^{5}$ In the setting of a prior lumbar fusion, degeneration is common ${ }^{27}$ and studies suggest it is the most common cause of post-fusion LBP. ${ }^{6,7}$ Even in those patients undergoing lumbar laminectomy alone, increased
Table 4 Adverse events

\begin{tabular}{|c|c|}
\hline Event & $\mathbf{N}$ \\
\hline \multicolumn{2}{|l|}{ Early adverse events (day $0-30$ ) } \\
\hline Back pain due to fall & I \\
\hline Bowel obstruction & I \\
\hline Buttock pain due to fall & I \\
\hline Buttock pain due to lifting heavy object & I \\
\hline Buttocks pain & 2 \\
\hline Cellulitis & I \\
\hline Contralateral knee meniscal injury due to fall & I \\
\hline Deep venous thrombosis & I \\
\hline Intraoperative hemorrhage & I \\
\hline Ipsilateral knee stiffness & I \\
\hline Late postoperative leg pain & I \\
\hline Lower back pain from sneeze, unrelated to SIJ & I \\
\hline Mild ipsilateral back pain & I \\
\hline Postoperative nausea & I \\
\hline Postoperative nausea/vomiting & I \\
\hline Upper respiratory tract infection & 2 \\
\hline Urinary tract infection & I \\
\hline Worsened knee pain & I \\
\hline Wound infection & I \\
\hline Wound redness & I \\
\hline Wrist injury from trauma & I \\
\hline Total & 23 \\
\hline \multicolumn{2}{|l|}{ Unknown time } \\
\hline Increased SI joint pain after PT & I \\
\hline \multicolumn{2}{|l|}{ Late adverse events (day $3 I+$ ) } \\
\hline A vascular necrosis of hip & 2 \\
\hline Trochanteric bursitis & 2 \\
\hline Upper respiratory infection & 2 \\
\hline Wound infection & 2 \\
\hline Worsening contralateral SI joint pain & 2 \\
\hline Anxiety & I \\
\hline Buttock pain due to postop physical therapy & I \\
\hline Cervical myelopathy & I \\
\hline Cholecystitis & I \\
\hline Choledocholithiasis & I \\
\hline Constipation & I \\
\hline Contralateral neck/arm pain & I \\
\hline Fall & I \\
\hline Gastrointestinal bleeding & I \\
\hline Groin pain of unclear etiology & I \\
\hline Hip pain due to fall & I \\
\hline Increased SI joint pain & I \\
\hline Ipsilateral hip pain & I \\
\hline Ischial tuberosity pain of unknown origin & I \\
\hline Leg edema related to pneumonia hospitalization & I \\
\hline Leg pain & I \\
\hline Limited knee extension related to old injury & I \\
\hline Pneumonia & I \\
\hline Worsened contralateral knee stiffness & I \\
\hline Total & 29 \\
\hline
\end{tabular}

Abbreviations: SI, sacroiliac; PT, physical therapy.

radionucleotide uptake has been demonstrated within the SI joint, suggesting altered spinal mechanics. ${ }^{28}$

Despite its frequency, diagnosis of SI joint conditions can prove difficult for a multitude of reasons, and no imaging modality has proven definitive in correlating symptoms 
with visible pathology. Compared to age-matched control patients, computerized tomography (CT) scan in patients with SI joint pain and positive diagnostic blocks was found to be only moderately sensitive (sensitivity $57.5 \%$ ) and moderately specific (69\%). ${ }^{29}$ While radionucleotide studies appear to be very specific $(89.5 \%-100 \%)$ their low sensitivity $(13 \%-46 \%)$ make them a poor screening tool. ${ }^{30,31}$ Diagnosis relies heavily on clinical history, provocative physical examination, and intra-articular injection. A systematic review concluded that, with the proper provocative testing, the SI joint could be identified as a pain generator with $85 \%$ sensitivity and $76 \%$ specificity. ${ }^{32}$ However, intra-articular injection remains the reference standard for diagnosis.

Noninvasive therapies for SI joint pain include rest, pain medications, physical therapy, chiropractic manipulation, and external orthotics (ie, pelvic belt or kinesiology tape). Physical therapy and osteopathic/chiropractic manipulation are mainstays in reducing SI joint pain and improving mobility and/or stability. While benefits have been demonstrated in those patients with altered gait mechanics and spinal alignment, prospective studies are lacking. ${ }^{33,34}$ Moreover, pain persists for many patients after non-invasive treatments have been used.

Intra-articular injections of the SI joint have two benefits. First, intra-articular anesthetic injection is considered the reference standard for diagnosing the SI joint as a pain generator. Meaningful improvement in SI joint pain immediately following injection is believed to be confirmatory in diagnosis. Intra-articular steroid administration has been shown in many studies to provide at least temporary symptomatic relief. ${ }^{35}$ Moreover, pain relief from peri-articular injections has also been demonstrated, but the diagnostic value is unknown. ${ }^{36,37}$ Radiofrequency ablation (RFA) using different methodologies (cooled RF, pulsed RF, intra-articular lesioning, as well as denervation) has also been used as a treatment modality for SI joint pain. Multiple reviews have demonstrated weak evidence supporting its use. ${ }^{38,39}$

For patients who have failed non-surgical care, surgical stabilization of the SI joint may be warranted. Many techniques have been described, with great variability in approach, outcomes, and complications. Early reports of open arthrodesis of the SI joint focused on technique descriptions. The few published retrospective $e^{8,9,11-14}$ cohorts suggest that open and more minimally invasive approaches to SI joint arthrodesis can be effective in relieving chronic LBP emanating from the SI joint but have high rates of complications $(13.7 \% \text { in one systematic review })^{10}$ and non-union $(9 \%-41 \%)^{8,11,12}$
We present here interim results from the first prospective, multicenter study demonstrating the safety and early effectiveness of a minimally-invasive SI joint fusion technique. All subjects enrolled had SI joint pain symptoms, positive findings on provocative maneuvers, confirmatory diagnostic intra-articular block, all resulting in a diagnosis of SI joint disruption or degeneration. Mid-term study follow-up showed significant reductions in pain and improvement in both the degree of disability due to back pain (as measure by ODI) and quality of life (as measured by SF-36 and EQ-5D). Perioperative morbidity was low and no unexpected events occurred. Importantly, there have been no device revisions or removals to date. The high mid-term response rate and acceptable perioperative safety profile confirm results from prior case series ${ }^{15-20}$ and a safety review ${ }^{40}$ of minimally invasive SI joint fusion using the same implant system reported herein. Study enrollment is continuing and further results will be reported after enrollment and follow up is complete.

This evaluation of the minimally invasive SI joint fusion with the iFuse has several advantages. The study controls the subject population by describing a pre-determined set of eligibility criteria and the results represent the experience of multiple centers. Institutional review boards for every clinical site approved the trial, and the trial was in compliance with an international clinical trial standard (ISO 14155:2011). The study population was carefully characterized. Data were collected on electronic case report forms in a structured fashioned at pre-determined postoperative time points and all data collected have been rigorously monitored and source verified.

The trial is limited by several considerations. First, the study lacks an active control group. However, given that all participating patients had chronic pain (a mean of 5 years of pain and at least 6 months of SI joint pain under the care of a physician) and had failed conservative care, the likelihood of high response rates with continued conservative management is likelihood low. Second, the study used ODI to assess baseline disability due to back pain and postoperative improvement related to pain. While ODI was designed for lower back pain and not SI joint pain, in the absence of validated SI joint instruments, ODI is a reasonable proxy, and improvements observed to date appear clinically significant. The improvements in ODI in this study were similar to those reported after percutaneous SI joint fusion. ${ }^{9}$ Similarly, the improvements in SF-36 quality of life scores were similar to those observed in a retrospective case series of patients undergoing percutaneous SI joint fusion using hollow modular anchorage screws plus demineralized bone matrix. ${ }^{14}$ 
Finally, while the procedure is termed arthrodesis and the goal of the procedure is to fuse the SI joint, the rate of SI joint fusion is not known. Radiographic analysis in the current study (based primarily on 1-year CT scan) is in progress and results will be reported elsewhere. These are of interest as the procedure used herein does not directly decorticate the joint and does not involve placement of bone graft.

\section{Conclusion}

Minimally invasive SI joint fusion using the iFuse Implant System ${ }^{\circledR}$ is safe and effective in patients with SI joint pain due to degenerative sacroiliitis and SI joint disruption. Mid-term follow-up indicates a clinically significant improvement in pain, function, and quality of life in this patient population. Patient satisfaction levels with the surgery were high. Study enrollment and follow up are ongoing.

\section{Acknowledgment}

SIFI Investigators and coordinators: Harry Lockstadt MD, Elaine Wilhite MS (Bluegrass Orthopaedics and Hand Care Research, Lexington, KY); Don Kovalsky MD, Laura Pestka RN (Orthopaedic Center of Southern Illinois, Mount Vernon, IL); CL Soo MD, Kallena Haynes, Tammy Hill (Health Research Institute, Oklahoma City, OK); Bradley Duhon MD, Amber Pfister CRC (Neurosurgical and Spine Specialists, Parker, CO); Craig Meyer MD, Vicki Jones (Columbia Orthopaedics Group, Columbia, MO); Mukund Gundanna MD, Jo Anna Richards RN (Brazos Spine, College Station, TX); Leonard Rudolf MD, John Thibodeau Jr RN (Alice Peck Day Memorial Hospital, Lebanon, NH); Andy Redmond MD, Jennifer Piazza (Precision Spine Care, Tyler, TX); Cheng Tao MD, Jackie Makowski (Spine and Neuro Center, Huntsville, AL); John Stevenson MD, Ana Marichal, (The Orthopaedic Institute, Gainesville, FL); Michael Hasz MD, Carrie Califano (Virginia Spine Institute, Reston, VA); Abhineet Chowdhary MD, Tina Fortney RN BSN (Overlake Hospital Medical Center, Bellevue, WA); Dmitriy Kondrashov MD, Nikolai Tarasov (St. Mary's Spine, San Francisco, CA); Jed Vanichkachorn MD, Jessica Lynch (Tuckahoe Orthopaedics Associates, Richmond, VA); William Rosenberg MD, Amy Akins RN BSN CCRC (Midwest Division-RMC, LLC,Research Medical Center, Kansas City, MO); John Gillespy MD, Sherri Zicker RN (Orthopaedic Clinic of Daytona Beach, Daytona Beach, FL); Kevin Stevenson MD, Logan Honeycutt LPN (Piedmont Orthopaedic Complex, Macon, GA); Gowriharan Thaiyananthan MD, Tungie Williams (BASIC Spine, Orange, CA); Ali Mesiwala MD, Stephanie Bose RN BSN (Southern California Center for Neuroscience and Spine, Pomona, CA); Ralph Rashbaum MD, Shannon Rusch BA CCRC (Texas Back Institute, Plano, TX); Fabian Bitan MD, Timolin Jeffers (Manhattan Orthopaedics, New York City, NY); Scott Kutz MD, Linda Thompson RN BSN (Mercy Medical Research Center, Springfield, MO).

\section{Disclosure}

Daniel J Cher and Kathryn D Wine are SI-BONE, Inc, employees, and Bradley S Duhon is a consultant to SI-BONE, Inc. The authors have no other conflicts of interest to report.

\section{References}

1. Carragee EJ, Ghanayem AJ, Weiner BK, Rothman DJ, Bono CM. A challenge to integrity in spine publications: years of living dangerously with the promotion of bone growth factors. Spine J. 2011;11(6): 463-468.

2. Tuite MJ. Sacroiliac joint imaging. Semin Musculoskelet Radiol. 2008;12(1):72-82.

3. Goldthwait JE, Osgood RB. A consideration of the pelvic articulations from an anatomical, pathological and clinical standpoint. Boston Med Surg J. 1905;152:593-601.

4. Bernard TN, Kirkaldy-Willis WH. Recognizing specific characteristics of nonspecific low back pain. Clin Orthop Relat Res. 1987:266-280.

5. Sembrano JN, Polly DW. How often is low back pain not coming from the back? Spine (Phila Pa 1976). 2009;34(1):E27-E32.

6. Liliang PC, Lu K, Liang CL, Tsai YD, Wang KW, Chen HJ. Sacroiliac joint pain after lumbar and lumbosacral fusion: findings using dual sacroiliac joint blocks. Pain Med. 2011;12(4):565-570.

7. DePalma MJ, Ketchum JM, Saullo TR. Etiology of chronic low back pain in patients having undergone lumbar fusion. Pain Med. 2011;12(5): 732-739.

8. Buchowski JM, Kebaish KM, Sinkov V, Cohen DB, Sieber AN, Kostuik JP. Functional and radiographic outcome of sacroiliac arthrodesis for the disorders of the sacroiliac joint. Spine J. 2005;5(5):520-528; discussion 529

9. Al-Khayer A, Hegarty J, Hahn D, Grevitt MP. Percutaneous sacroiliac joint arthrodesis: a novel technique. J Spinal Disord Tech. 2008;21(5): 359-363.

10. Ashman B, Norvell DC, Hermsmeyer JT. Chronic sacroiliac joint pain: fusion versus denervation as treatment options. Evid Based Spine Care J. 2010;1(3):35-44

11. Waisbrod H, Krainick JU, Gerbershagen HU. Sacroiliac joint arthrodesis for chronic lower back pain. Arch Orthop Trauma Surg. 1987;106(4): $238-240$.

12. Schütz U, Grob D. Poor outcome following bilateral sacroiliac joint fusion for degenerative sacroiliac joint syndrome. Acta Orthop Belg. 2006;72(3):296-308.

13. Wise CL, Dall BE. Minimally invasive sacroiliac arthrodesis: outcomes of a new technique. J Spinal Disord Tech. 2008;21(8):579-584.

14. Khurana A, Guha AR, Mohanty K, Ahuja S. Percutaneous fusion of the sacroiliac joint with hollow modular anchorage screws: clinical and radiological outcome. J. Bone Joint Surg. Br. 2009;91:627-631.

15. Rudolf L. Sacroiliac Joint Arthrodesis-MIS Technique with Titanium Implants: Report of the First 50 Patients and Outcomes. Open Orthop J. 2012;6:495-502.

16. Rudolf L. MIS Fusion of the SI Joint: Does Prior Lumbar Spinal Fusion Affect Patient Outcomes? Open Orthop. J. 2013;7:163-168.

17. Sachs D, Capobianco R. One year successful outcomes for novel sacroiliac joint arthrodesis system. Ann Surg Innov Res. 2012; 6(1):13.

18. Sachs D, Capobianco R. Minimally invasive sacroiliac joint fusion: one-year outcomes in 40 patients. Adv Orthop. Epub 2013, August 13. 
19. Smith AG, Capobianco R, Cher D et al. Open versus minimally invasive sacroiliac joint fusion: a multi-center comparison of perioperative measures and clinical outcomes. Ann Surg Innov Res. 2013;7(1):14. Epub ahead of print.

20. Cummings Jr J, Capobianco R A. Minimally invasive sacroiliac joint fusion: one-year outcomes in 18 patients. Ann Surg Innov Res. $2013 ; 7 ; 12$.

21. SI-BONE, Inc., Sacroiliac Joint Fusion With iFuse Implant System ${ }^{\circledR}$ (SIFI). Available from: http://clinicaltrials.gov/show/NCT01640353N LMidentifier:NCT0140353. Accessed November 5, 2013.

22. Fairbank JC, Pynsent PB. The Oswestry Disability Index. Spine (Phila Pa 1976). 2000;25(22):2940-2952; discussion 2952.

23. EuroQol Group. EuroQol - a new facility for the measurement of health-related quality of life. Health Policy. 1990;16(3):199-208.

24. Ware JE, Sherbourne CD. The MOS 36-item short-form health survey (SF-36). I. Conceptual framework and item selection. Med Care. 1992;30(6):473-483.

25. Childs JD, Piva SR, Fritz JM. Responsiveness of the numeric pain rating scale in patients with low back pain. Spine (Phila Pa 1976). 2005; 30(11):1331-1334.

26. Mixter W, Barr J. Rupture of the intervertebral disc with involvement of the spinal canal. N Engl J Med. 1934;211:210-215.

27. Ha KY, Lee JS, Kim KW. Degeneration of sacroiliac joint after instrumented lumbar or lumbosacral fusion: a prospective cohort study over five-year follow-up. Spine (Phila Pa 1976). 2008;33(11): 1192-1198.

28. Onsel C, Collier BD, Kir KM, et al. Increased sacroiliac joint uptake after lumbar fusion and/or laminectomy. Clin Nucl Med. 1992;17(4): 283-287.

29. Elgafy H, Semaan HB, Ebraheim NA, Coombs RJ. Computed tomography findings in patients with sacroiliac pain. Clin Orthop Relat Res. 2001;112-118.

30. Slipman CW, Sterenfeld EB, Chou LH, Herzog R, Vresilovic E. The value of radionuclide imaging in the diagnosis of sacroiliac joint syndrome. Spine (Phila Pa 1976). 1996;21(19):2251-2254.
31. Fortin JD, Dwyer AP, West S, Pier J. Sacroiliac joint: pain referral maps upon applying a new injection/arthrography technique. Part I: Asymptomatic volunteers. Spine (Phila Pa 1976). 1994;19(13): 1475-1482.

32. Szadek KM, van der WurffP, van Tulder MW, Zuurmond WW, Perez RS. Diagnostic validity of criteria for sacroiliac joint pain: a systematic review. J Pain. 2009;10(4):354-368.

33. Cibulka MT, Delitto A. A comparison of two different methods to treat hip pain in runners. J Orthop Sports Phys Ther. 1993;17(4): $172-176$.

34. Osterbauer PJ, De Boer KF, Widmaier R, Petermann E, Fuhr AW Treatment and biomechanical assessment of patients with chronic sacroiliac joint syndrome. J Manipulative Physiol Ther. 1993;16(2): $82-90$

35. Cohen SP, Chen Y, Neufeld NJ. Sacroiliac joint pain: a comprehensive review of epidemiology, diagnosis and treatment. Expert Rev Neurother. 2013;13(1):99-116.

36. Luukkainen RK, Wennerstrand PV, Kautiainen HH, Sanila MT, Asikainen EL. Efficacy of periarticular corticosteroid treatment of the sacroiliac joint in non-spondylarthropathic patients with chronic low back pain in the region of the sacroiliac joint. Clin Exp Rheumatol. 2002;20(1):52-54

37. Luukkainen R, Nissilä M, Asikainen E, et al. Periarticular corticosteroid treatment of the sacroiliac joint in patients with seronegative spondylarthropathy. Clin Exp Rheumatol. 1999;17(1):88-90.

38. Rupert MP, Lee M, Manchikanti L, Datta S, Cohen SP. Evaluation of sacroiliac joint interventions: a systematic appraisal of the literature. Pain Physician. 2009;12(2):399-418.

39. Cohen SP. Sacroiliac joint pain: a comprehensive review of anatomy, diagnosis, and treatment. Anesth Analg. 2005;101(5):1440-1453.

40. Miller LE, Reckling WC, Block JE. Analysis of postmarket complaints database for the iFuse SI Joint Fusion System ${ }^{\circledR}$ : a minimally invasive treatment for degenerative sacroiliitis and sacroiliac joint disruption. Med Devices (Auckl). 2013;6:77-84.
Medical Devices: Evidence and Research

\section{Publish your work in this journal}

Medical Devices: Evidence and Research is an international, peerreviewed, open access journal that focuses on the evidence, technology, research, and expert opinion supporting the use and application of medical devices in the diagnosis, treatment and management of clinical conditions and physiological processes. The identification of novel

\section{Dovepress}

devices and optimal use of existing devices which will lead to improved clinical outcomes and more effective patient management and safety is a key feature. The manuscript management system is completely online and includes a quick and fair peer-review system. Visit http://www. dovepress.com/testimonials.php to read real quotes from authors. 